\title{
Tecido Adiposo: \\ Uma Breve Perspectiva Histórica e o Momento Atual
}

A HISTÓRIA DA CIÊNCIA É RICA em exemplos de concepções equivocadas que se revelaram prejudiciais com conseqüências ruins para a Humanidade. Em biologia, a idéia errônea sobre o papel do tecido adiposo (TA) é um exemplo. Durante muito tempo, pensou-se ser uma estrutura secundária cuja característica mais marcante era possuir notável capacidade de armazenar grandes quantidades de gordura na forma de triacilgliceróis. Em indivíduos com peso corporal dentro da normalidade (índice de massa corporal entre 18,5 e $25 \mathrm{~kg} / \mathrm{m}^{2}$ ), essa reserva gira ao redor de $120.000 \mathrm{kcal}$. Além dessa particularidade, atribuíam-se ao TA duas atividades básicas: a lipogênese (que possibilita acumular reservas energéticas) e a lipólise (para suprir energia em momentos de maior demanda ou de carência nutricional). Pouco se atentou para outro aspecto funcional - a sua participação no controle do peso corporal e da ingestão alimentar. Pistas sobre essa particularidade funcional existem na literatura pertinente em trabalhos da década de 1950-1960, quando Kennedy propôs uma teoria metabólica para explicar o controle do comportamento alimentar denominada de teoria lipostática (1). Em síntese, este autor, estudando ratos, propunha que o TA participava do controle do consumo alimentar mediante a liberação de fatores circulantes (admitia-se que fossem ácidos graxos livres) que, com a insulina, agiam sobre o hipotálamo (possivelmente, o núcleo ventromedial, naquela época conhecido como centro da saciedade) inibindo ou refreando a ingestão de alimentos. Essa teoria, embora engenhosa e apoiada em inúmeros trabalhos, pouca atenção despertou; teve discreta repercussão e foi esquecida, até que, nos anos 1990, com a descoberta da leptina por Zhang e cols. (2), inaugurou-se uma nova era de estudos sobre o TA, como órgão endócrino (3). A partir daí, a leptina foi associada ao controle do peso corporal, pois camundongos $o b / o b$, portadores de uma mutação disfuncional do gene da leptina, eram obesos e tinham apetite voraz. O tratamento com leptina reduzia a ingestão alimentar e o peso corporal. Com isto, a teoria lipostática retornou sob nova roupagem. Trabalhos de Ahima e Flyer (4) permitiram a seguinte releitura da teoria lipostática: a leptina (e não os ácidos graxos livres) liberada pelos adipócitos, com a insulina, agiriam sobre o núcleo arqueado (em vez do ventromedial), ativando populações de neurônios anorexígenos aí localizados (que expressam pro-opio-melano-cortina [POMC] e transcrito regulado por cocaína e anfetamina [CART]) e inibindo outros neurônios orexígenos (que expressam neuropeptídeo Y [NPY] e proteína Agouti-relacionada [AgRP]). O sinergismo entre leptina e insulina foi confirmado por muitos estudos, entre os quais os de Carvalheira e cols. (5), estudando a sinalização intracelular de insulina e de leptina em hipotálamo de ratos, que mostra intenso crosstalk entre os dois hormônios. Hoje, o estudo sobre o controle do peso e do comportamento alimentar atingiu alto grau de complexidade (ver a revisão a respeito) (6).

Este breve histórico revela que o TA possui admirável capacidade de "conversar" com outras estruturas, notadamente com o sistema nervoso cen- editorial

FABIO BESSA LIMA

Professor Titular do Departamento de Fisiologia e Biofísica da Faculdade de Medicina da Universidade de São Paulo, SP, Brasil 
tral, e este é o seu grande papel funcional. Entender esta "conversa" química promete ser o grande aspecto dos estudos funcionais sobre o TA nos próximos anos.

A esse respeito, pode-se dizer que o TA recebe ("compreende") uma gama enorme de mensagens químicas, pois possui receptores para um elevado número de hormônios oriundos dos mais diversos órgãos endócrinos (vide a seguinte revisão ${ }^{7}$ ) e, por sua vez, os adipócitos liberam no meio interno outro igualmente elevado número de mensagens químicas, denominadas adipocinas. Muitas destas adipocinas "conversam" com células localizadas na sua imediata vizinhança, desempenhando importante efeito parácrino. Outras se difundem pela circulação, atingindo territórios mais distantes executando funções endócrinas. Em síntese, a célula adiposa reconhece inúmeras mensagens, as interpreta adequadamente e envia mensagens (adipocinas) a outras células. Poucas células no organismo têm tal habilidade e é essa a nova dimensão que o TA vem ganhando.

Chamo ainda a atenção para outro aspecto curioso: esse tecido tem a propriedade de se expandir e de "invadir" outros territórios. Muitas observações dão conta do crescimento de massa adiposa no interior ou nas proximidades de vísceras e músculos. Em parte, essa infiltração adiposa se dá ao acompanhar o trajeto de vasos sangüíneos, pois vem sendo muito descrita a presença de TA perivascular. Isto merece especial atenção porque indica que o TA não somente envia suas adipocinas a células distantes do local de produção, mas, ao se infiltrar em outros territórios, desencadeia uma conversa local. O TA perivascular, por exemplo, produz fatores vasoativos com importante função parácrina (8).

Nesta edição da revista, um interessante trabalho $(A$ bypercaloric pellet-diet cycle induces obesity and co-morbidities in Wistar rats) (9) é apresentado, no qual os autores, manipulando dieta de ratos, provocaram obesidade. O aumento generalizado da adiposidade foi acompanhado de elevação da insulinemia e da leptinemia, além de outras alterações metabólicas, como ligeira hiperglicemia e hipertrigliceridemia. Foram observados maior ganho de peso corporal e redução da ingestão alimentar, mostrando importante ganho na eficiência alimentar. O ganho em adiposidade se acompanhou de aumento de leptinemia e insulinemia com desenvolvimento concomitante de resistência à insulina. Pode-se especular que leptina e insulina elevadas geram redução da ingestão alimentar a fim de combater ou atenuar os riscos que o quadro de síndrome metabólica em progressão representa. Esse estudo é, portanto, um excelente modelo para investigar comportamento alimentar e controle do peso corporal, e suas relações com o desenvolvimento da síndrome metabólica. Esse modelo pode ser uma importante ferramenta experimental para abordar a característica multifacetada da obesidade e de suas comorbidades.

Compreender o papel funcional do TA significa entender sua habilidade em "conversar" com os demais tecidos. Como os autores mencionam na sua introdução do artigo, obesidade é um problema de saúde pública de proporções gigantescas tanto em países desenvolvidos como naqueles em franco desenvolvimento, como o Brasil. O combate requer não só a intervenção de políticas públicas de controle de agentes obesogênicos e uma importante atuação na área de educação alimentar, mas há a necessidade de se compreender o TA e sua relação com o SNC no controle do comportamento alimentar.

\section{REFERÊNCIAS}

1. Kennedy GC. Hypothalamic obesity. Proc Royal Soc Med. 1966;153:1276-7.

2. Zhang Y, Proenca R, Maffei M, Barone M, Leopold L, Friedman JM. Positional cloning of the mouse obese gene and its human homologue. Nature. 1994;372:425-31.

3. Fruhbeck G, Gómez-Ambrosi J, Muruzábal FJ, Burrell MA. The adipocyte: a model for integration of endocrine and metabolic signaling in energy metabolism regulation. Am J Physiol Endocrinol Metab. 2001;280:E827-47.

4. Ahima RS. Central actions of adipocyte hormones. TEM. 2005;16:307-13.

5. Carvalheira JBC, Ribeiro EB, Araújo EP, Guimarães RB, Telles $M M$, Torsoni $M$, et al. Selective impairment of insulin signalling in the hypothalamus of obese Zucker rats. Diabetologia. 2003;46:1629-40.

6. Angelopoulos N, Goula A, Tolis G. Current knowledge in the neurophysiologic modulation of obesity. Metabolism. 2005;54:1202-17.

7. Kershaw EE, Flyer JS. Adipose Tissue as an Endocrine Organ. J Clin Endocrinol Metab. 2004;89:2548-56.

8. Gusik TJ, Marvar PJ, Czesnikiewicz-Guzik M, Korbut R. Perivascular adipose tissue as a messenger of the brain-vessel axis: role in vascular inflammation and dysfunction. J Physiol Pharmacol. 2007;58:591-610.

9. Nascimento AF, Sugizaki MM, Leopoldo AS, Lima-Leopoldo AP, Luvizotto RAM, Nogueira CR, Cicogna AC. A hypercaloric pellet-diet cycle induces obesity and co-morbidities in wistar rats. Arq. Bras. Endocrinol. Metab. 2008;52:968-74.

\section{Endereço para correspondência:}

Fabio Bessa Lima

Av. Prof Lineu Prestes, 1.524

05508-900, São Paulo, SP

E-mail: fabio@icb.usp.br 